\title{
Gender in the American Anthology Apparatus: A Linguistic Analysis
}

\author{
Laura Aull \\ English Department, Wake Forest University, Winston Salem, USA \\ Email: aulll@wfu.edu
}

Received November $23^{\text {rd }}, 2013$; revised December $26^{\text {th }}$, 2013; accepted January $13^{\text {th }}, 2014$

\begin{abstract}
Copyright ( 2014 Laura Aull. This is an open access article distributed under the Creative Commons Attribution License, which permits unrestricted use, distribution, and reproduction in any medium, provided the original work is properly cited. In accordance of the Creative Commons Attribution License all Copyrights (C) 2014 are reserved for SCIRP and the owner of the intellectual property Laura Aull. All Copyright (c) 2014 are guarded by law and by SCIRP as a guardian.
\end{abstract}

\begin{abstract}
Most American anthology and canon revision has focused on author and text selections but little on the anthology editorial apparatus. The following study responds to this gap by analyzing gender representation across prefaces and overviews of the Norton and Heath American anthologies (1979-2010). Through a combined rhetorical and corpus linguistic analysis, the study reveals disparate gender representation in these materials: women are increasingly mentioned over time, but men continue to emerge as individuals of importance while women are discussed primarily as a group. This examination suggests that the revisionist, feminist scrutiny of Norton and Heath inventory has not been brought to bear on the anthologies' apparatus - and that discursive patterns therein remain largely invisible despite that they contradict efforts to revise gender bias in anthologies. In so doing, the study offers an exploratory analysis of new methods (combined linguistic and rhetorical analysis) and new sites (apparatus texts) for examining gender in canonical and pedagogical materials.
\end{abstract}

Keywords: Gender; American Anthologies; American Canon; Linguistic Analysis

\section{Introduction}

That women's contributions which should be acknowledged in American anthologies is by now established. Survey anthologies have been extensively revised, and the American anthology itself-as artifact and architect of inclusions, exclusions, and values - is more problematized than ever. It is a canonical, national story for the field's widest audience (Graff, 1987; Shumway, 1994b), a place for challenging and rethinking the values and structures that have excluded marginalized voices (Rosenfeld, Hames-Garcia), a "political and educational tool” (Lockard \& Sandell, 2008: pp. 246-249), and is ever contingent and contextualized by editors and institutional contexts (Guillory, 1993, p. 29). It is at the same time "very widely used yet very little theorized" (Chaney, 192), a commercial object whose material production remains mystified and potentially marked by a “double life” (Shesgreen, 2009).

In 30 years of problematizing anthologies, the primary response has changed anthology inventory, and thus the tables of contents of contemporary survey anthologies bear an equal number of female and male authors. Any recent edition of the two leading survey anthologies, the Norton and Heath anthologies of American Literature, shows this shift. What is less clear is the representation of gender in apparatus narratives like the prefaces and overviews. As women authors have been more represented in their tables of contents, have they also been represented more in the anthologies' stories of edition and nation? In such narratives, are women still marginal to US literary history? Or do they alter or enhance it?
Along with the inventory focus of anthology revisions, there are at least two explanations for little analysis of gender in the anthology apparatus. First, despite that editorial discourse also helps re/construct a particular kind of canon, anthology editorial texts are seen as pedagogical and therefore apolitical and unimportant (Aull, 2012). Second, there are no anthology studies that systematically analyze the apparatus materials. They often highlight editorial introductions, especially prefaces, as part of anthology examination ${ }^{1}$, but they do so by examining ideas and language in individual texts rather than across them. Approaches that look across many texts such as corpus linguistics have not been used in anthology study, despite the scrutiny of anthology inventory in the late $20^{\text {th }}$ century and despite corpus linguistic analysis of literary texts ${ }^{2}$. Resulting limitations -in our knowledge of how gender representation in American anthologies has evolved (or not)—are twofold: 1) we have little analysis of editorial representation of women and men in anthologies; and, more generally, 2) we have little knowledge of how recurring patterns of pedagogical discourse construct gender.

\section{A New Kind of Anthology Analysis}

Taking up the premise that editorial anthology discourse

\footnotetext{
1e.g., see: Arac, 2008; Brown, 2010; Csicsila, 1998; Dyer, 2001; Egan, 1997 Elmer, 2008; Graff, 1987; P. Lauter, 1991; Lockard \& Sandell, 2008; Papadima, Damrosch, \& D’haen, 2011; Ruland, 1991; Shumway, 1994a). ${ }^{2}$ Corpus linguistics facilitates analysis of large bodies of comparative texts with the help of computer-based tools. See endnote 4 for more detail.
} 
speaks to embedded national and disciplinary beliefs about women and men, the following analysis begins to explore what those beliefs seem to be and, more exceptionally, how they are realized in language patterns across time in the Heath and Norton American anthologies. Among other editorial materials, the anthology preface (the story of the anthology and edition) and the period overview (the story of American national and literary history by periods) construct an overarching narrative of anthology and nation and comprise what I refer to as the apparatus $^{3}$. Like the prefaces, the period overviews are a kind of paratext, a "privileged site of a pragmatics and a strategy" that strives to act upon readers "a more pertinent reading-more pertinent, naturally, in the eyes of the author and [his/her] allies" (Genette \& Maclean, 1991: pp. 261-262). While the overviews offer a periodized narrative that places the subsequent texts in an ultimately promotional national story, the prefaces offer a promotional frame for the anthology and edition as a whole. Both intimate a mediating, authoritative role and pertinent reading. They articulate what one needs to know about the US and the anthology in order to read its literature meaningfully, and their discourse helps reflect and realize particular assumptions about the nation, its literatures, and literary study. I refer to the prefaces and overviews as the apparatus because they part of a larger machine (the anthology) while also constituting a mechanism in and of themselves; they are in this way paratextual as well as textual.

In order to look over time and across more than one anthology, the following analysis examines all prefaces and overviews of the Norton and Heath anthologies of American literature, from the first publication (1979) to the most recent (2010). These two are by no means the only survey anthologies; but they are valuable here because they are the most adopted survey anthologies and are regularly evoked as representations of a more "traditional" (Norton) and "reformist" (Heath) approach to greater inclusion of women and other historically-marginalized groups (Arac, 2008; Bennett, 1991; Elmer, 2008; Jay, 1991; Lockard \& Sandell, 2008) ${ }^{4}$. The analysis draws on both corpus (computer-aided) linguistic and rhetorical approaches in order to illuminate patterns in individual texts as well as across texts and over time. The study's limitation to only these two conventional survey anthologies therefore enables an in-depth look across 30 years of changes in two widely-adopted and

\footnotetext{
${ }^{3}$ At the same time, it is important to note that the other texts surrounding them influence the ways that these editorial texts function; I identify all of the following as texts that function both independently and interdependently in American literature anthologies. This study focuses on 7 and 8 but provokes questions about the others as well. 1) Anthology cover and binding; 2) Title pages and publishing information (what Genette calls the publishers' "peritext", though I separate the cover from these); 3) Table of contents; 4) Word, title, and author indexes; 5) Citations (bibliographic information and copyright notices); 6) Author biographies; 7) Preface to the anthology; 8) Historical period overviews; 9) Legal historical documents (e.g., The Declaration of Independence); 10) Prose categorized as literature (e.g., short stories and novels); 11) Poetry categorized as literature; 12) Photographic representations (aside from the cover).

${ }^{4}$ To enable this approach, I digitized all prefaces and period overviews of all editions of the Norton and Heath Anthologies of American Literature since their respective beginnings in 1979 and 1989. This process made each preface and period overview (including subsections) available in pdf form as well as character-recognizable text files, which I analyzed with the help of AntConc concordance software (Anthony, 2005). Anthology citations are as follows: (Nina Baym, 1989; Nina Baym, 1995, 1998, 2002b; N. Baym, et al. 2007; N. Baym, et al., 1985; Gottesman et al., 1979; P. Lauter \& Bruce, 1990; P. Lauter, et al., 2002, 2005, 2009; P. Lauter, Yarborough, \& Bruce, 1994, 1998).
}

allegedly-opposed anthologies.

A rhetorical and linguistic analysis of these anthologies' prefaces and overviews shows that women are now mentioned more frequently, but in ways that should give us pause, particularly inside anthologies that claim to revise women's representation in the US canon. These patterns suggest that the relative invisibility of the apparatus has permitted more "inclusive", but reductive and inequitable, representations of women and men.

This essay thus aims to underscore that the apparatus is a part of the cultural narratives of anthologies, but to more importantly expose subtle, asymmetrical gender representations in the apparatus that oppose the espoused values of the anthologies. In the first aim, I hope to cast the more often-studied anthology literary genres as part of a "broader intertextual process" that includes the apparatus - as part of a larger system of genres in which all texts function (Frow, 2006: p. 142). At the same time, this analysis demonstrates that anthology apparatus texts are themselves unique sites of contested versions of American culture and canon, not least because prefaces narrate anthologies' involvement in canon discussions and period overviews frequently do "recovery" work for groups traditionally underrepresented in US literary history ${ }^{5}$. Accordingly, this analysis focuses on individual editorial texts but also recurring patterns across them that are otherwise difficult to note in traditional analytic methods. In so doing, it offers an exploratory illustration of new sites (apparatus materials) and new methods (combined linguistic and rhetorical analysis) for examining gender representation in American anthologies.

\section{Analysis of Gender Pro/Nouns in the Norton and Heath Apparatus}

The first Norton edition in 1979 boasts that it includes a revolutionary twenty-nine women (out of over 90 authors) in order to "redress the long neglect of women writers"; Norton still later published the Norton Anthology of Literature by Women in response to feminist critiques about the nature and narrowness of the Norton's "inclusions" (Lockard \& Sandell, 2008). The first Heath preface (as well as its preceding project Reconstructing American Literatures) asked, "where are the women?" as a key premise for the creation of the Heath, and Lauter and his colleagues emphasized the need for courses that made women and "crucial female experiences" more visible (1983: p. xvi). Just as representation of women and men has been a key issue in canon debates, these examples highlight the importance of the issue of gender representation for publishers, editors, teachers, scholars, and students involved in the production and use of American Literature anthologies.

According to the notion that their selected literary authors and texts primarily define an anthology, examples like the Norton and the Heath have now heeded or even initiated demands for equal representation. What is less transparent is the representation in the anthology apparatus: do the period overviews and the prefaces offer a balanced account of the importance of female and male figures in US literary history? Given each anthology's self-articulations as well as decades of feminist critique of anthologies, it seems reasonable to assume there

\footnotetext{
$\overline{{ }^{5} \text { As an illustration: later editions of the Norton include subsections that often }}$ detail experiences of underrepresented groups; e.g. the subsection overview entitled "Native Americans: Removal and Resistance" in the Norton $7^{\text {th }}$ edition, volume B (1820-1865); I offer other examples, such as "the Woman Question" subsections in the Heath, in the analysis below.
} 
is minimal representation of women in early Norton apparatus texts and then increasingly balanced representation in later ones, and that the Heath achieves this goal earlier and more consistently. Given that personal pronouns (she, he, his, him, her) and gendered nouns (man/en, woman/en) are used to refer to antecedent nouns or noun phrases (often at considerable length), the discursive manifestation would be that gendered pro/nouns would at first be dominated by the masculine forms (especially in the Norton) and would in later editions be more or less equal $^{6}$.

Examining the use and quantity of these gendered nouns and pronouns is one way to explore the breadth and depth of coverage of important figures in apparatus discourse ${ }^{7}$. A premise underlying this approach is that discourse as well as details shape the representation of social groups and individuals-and not always in readily-obvious ways. That is, it not only matters that women are mentioned in historical accounts in an anthology; the cumulative effect of subtle discourse patterns also matters. Below, I map out gendered noun and pronoun patterns in individual Norton and Heath texts first, in order to show how disparate patterns are realized in single texts. The global, corpus patterns offered subsequently show how frequently these patterns occur over time and texts. The order of sections below, however, is only for the sake of clarity and reader familiarity; the analysis itself was far more recursive; each analytic approach informed and overlapped with the other.

\section{How Gendered Pro/Nouns Operate in the Apparatus}

As in other written texts, quantities of personal pronouns in the Norton and Heath prefaces and overviews correspond to the detail afforded to the pronouns' antecedents. For example, in the following two sentences from early $19^{\text {th }}$ century period overviews, the first characterizes a writer in more detail than the second, and there are also more personal pronouns in the first (emphasis mine):

When the newly unemployed Hawthorne remarked in "The Custom-House" preface to The Scarlet Letter that his Puritan ancestors would have been aghast at the thought that he was a mere "writer of storybooks", he was also speaking to his self-conscious sense that he was failing to live up to contemporary expectations of manly republican authorship (Norton $7^{\text {th }}$ ).

Harriet Jacobs survives the rigors of nearly seven years hiding in an attic through the support of her family, which, much of the time, she can only hear (Heath $6^{\text {th }}$ ).

Predictably, in anthology period overviews, singular nouns and pronouns refer to important individual figures, most often writers, in order to facilitate elaboration. Many of the words surrounding these singular pro/nouns are similar regardless of whether they refer to males or females; they primarily describe the writer's influences and experiences with artistic movements and cultural events. In the Heath (all overviews, all editions), for example, two of the most frequent nouns that collocate (or

\footnotetext{
${ }^{6}$ Other gendered plural referents, such as ladies and gentlemen or boys and girls, appeared too rarely in the anthologies to be of the same significance, and so they are not included here.

${ }^{7}$ Another question I had was whether or not "he", "his" or "man/men” were used in generic terms to refer to individual and collective human beings in the anthologies. With the exception of material quoted by the editors, these terms are not used in this way except in the Norton $1^{\text {st }}$ and $2^{\text {nd }}$ editions, in which "man" is used a few times as a synonym for "human"; the other terms are very rarely used generically, hence my focus on he, she, her, his, him, women, and men.
}

co-occur) with her are "life" and "husband", and two of the most frequent nouns collocating with his are "life" and "wife". Singular pronouns often emerge in descriptions of the intersection between writers' lives and writing, such as in the following two examples from the Norton $7^{\text {th }}$ edition $1914-1945$ period overview: "Just as his contemporaries in poetry and fiction were changing and questioning their forms, so Eugene O'Neill sought to refine his. He experimented..."; and "Zora Neale Hurston drew on her childhood memories of the all-black town of Eatonville, Florida, for much of her best-known fiction..." (emphasis mine).

In addition to facilitating descriptions of key figures, editors use personal pronouns as they foreground key texts. For example, in the following passage, Norton editors indicate the importance of the following texts during the 1914-1945 period they title "American literature between the wars":

Many writers of the post-Civil War period were still active in the 1920s and 1930s: for example, Hamlin Garland, the spokesman for literary naturalism, wrote his four-volume autobiography between 1917 and 1930; Edith Wharton published her masterpiece, The Age of Innocence, in 1920 (Norton $3^{\text {rd; }}$ emphasis mine).

As in descriptions of writers' influences, pronouns around descriptions of key texts are used similarly whether in descriptions of male or female figures.

Finally, pronouns also appear in overviews in service of elaboration on literary figures vis-à-vis larger movements or historical moments, though these do not always play out equally for women and men. Individual women, unlike men, are most often characterized in light of their collective gendered group's experience in the given literary or historical moment. For example, in the Heath overview of the early nineteenth century ( $6^{\text {th }}$ edition), the editors write that Emerson's "The American Scholar" signified a "turning point in our culture" by marking the beginning of the "American Renaissance". The narrative goes on to describe Henry Wadsworth Longfellow: "As reviewer and arbiter of literary taste, he would also significantly shape the reputations and careers of American writers, including most notably those of his fellow Bowdoin graduate, Nathaniel Hawthorne”. The description then mentions Oliver Wendell Holmes' poetry and also Angelina Grimké, who "had issued her tract Appeal to the Christian Women of the South" and thus "extended women's participation in the political and literary life of the republic" (emphasis mine). As the passage continues, it narrates the publications of John Greenleaf Whittier, Elijah P. Lovejoy, and Frederick Douglass, all as individual contributions. The rhetorical organization of the above passage is a significant and common one in the anthology apparatus: the editors describe a literary moment, including many male authors that help define it; when editors mention a female author in that same moment, they often characterize her according to her defining social group, women. The pronouns and nouns above reflect this pattern: singular pronouns he, his, and her, serve elaboration about an author (e.g., details about Longfellow and Grimké), and the plural noun (women) signals detail about a gendered group.

The rhetorical moves that make such gendered discrepancies possible sometimes follow the pattern of the Grimké example above: a period or movement is introduced, including individuals who defined that moment; within that description, women are mentioned as a group vis-à-vis that moment, often as an elaboration of the work of an individual woman (if mentioned). 
Perhaps the most obvious form this pattern can take is the form of a broader section (e.g. "American literature 1820-1865”) with a subsection devoted to "Women writers" or "the Woman Question”. For example, in the Heath $1^{\text {st }}$ edition, the 1865-1910 overview lays out the whole period, then moves into a "Publishing and Writing" subsection, followed by "Women Writers" as the subsequent subsection. The "Women Writers" subsection begins:

The most important pre-Civil War woman writer, Emily Dickinson, had been a recluse all her life. But the single most significant fact about women as a group in the post-war period was undoubtedly their visibility, as they increasingly moved outside the home to claim a place in the public world (Heath $1^{\text {st }}$ 1865-1910).

This passage categorizes Emily Dickinson as a woman writer and then continues on to make a generalization about women during the period-one that is apparently more significant and generalizable than Dickinson's reclusiveness. In later Heath editions $\left(2^{\text {nd }}-6^{\text {th }}\right)$, a similar subsection is entitled "Literature and the 'Woman Question"” or "Circumstances and Literary Achievements of Women". Interestingly, in the $5^{\text {th }}$ and $6^{\text {th }}$ editions of the Heath, Emily Dickinson is no longer used as a transition, and the above generalization is revised to read: "But the single most significant fact about women, especially white, middle-class women, as a group in the post-war period was their visibility..." (emphasis mine). Though still addressing women in terms of their collective "visibility", this revision includes a qualification in terms of race and class as well as a removal of "undoubtedly" from the earlier text.

The discursive pattern of introducing a period and then addressing "women" in that same moment occurs without explicit subsections as well. For example, the Norton $7^{\text {th }}$ edition overview of “American Literature since 1945" introduces the Sixties as "really" beginning with the assassination of John F. Kennedy and then describes women, in broad strokes, at that same time: "For the first time since the Suffrage movement following World War I, women organized to pursue their legal, ethical, and cultural interests, now defined as feminism”. In another example, this time from the Heath, editors name individual male writers but address women as a group in order to characterize (and contrast) men and women in the 1945-present subsection entitled "The 'American Century': From Victory to Vietnam”. The overview states:

Poor, marginalized men like Ellison, Baldwin, Kerouac, and Ginsberg struggled to get their experiences and visions into print, but women writers of the 1950s and 1960s were also revealing a widespread resistance to the cultural expectations, especially those that would keep them barefoot, pregnant, and in the kitchen (Heath $6^{\text {th }} 1945$-present).

After this description, the editors mention Betty Friedan's "The Feminine Mystique" in terms of its exploration of "the discontentment that so many middle-class women were experiencing" (but do not offer details about Friedan's life as an individual). In a similar example, the Norton $5^{\text {th }}$ edition $1620-1820$ overview mentions the beliefs of three individual men-Freneau, Franklin, and Crevecoeur-during Enlightenment in the US. As a result of such ideas, the passage intimates, women responded: "Fired by Enlightenment ideals of reason and equality, women began to speak and write on public subjects and to agitate for their rights as citizens"; the passage then returns to individual men, describing that "In many ways it is Franklin who best represents the spirit of the Enlightenment in America: self-educated, social, assured, a man of the world, ambitious and public-spirited...”

Other examples of references to women as a group include more general descriptions like: "more women than ever in American history are writing fiction, memoir, cultural and social criticism..." (Norton $7^{\text {th }}$ ); "cultural norms for women" (Heath $6^{\text {th }}$ ); or the famous quote by Hawthorn, reprinted in the Norton $1^{\text {st }}, 2^{\text {nd }}, 3^{\text {rd }}$, and $4^{\text {th }} 1820-1865$ period overview and the 1800-1865 overview of every edition of the Heath: "that damned mob of scribbling women”. In contrast, men as a group are more often talked about in conjunction with women, in terms of society or human beings more generally (e.g., "In the United States, as the nineteenth century drew to a close, as the men and women who wrote..." [Heath $\left.6^{\text {th }}\right]$ ).

In sum, then, editors use personal pronouns to offer more detail about individual figures of importance, vis-à-vis events, movements, and texts, and, when used, the singular pronouns are similar whether referring to females or males; they enable elaboration about the lives and experiences of national and literary figures without restating names. But a closer look across anthology period overviews, elucidated in the next section, shows that in quantity, there are differences: there are far more singular male pronouns, and individual males are covered in more detail than individual females. In contrast, plural gendered references show the opposite pattern. Women are discussed far more often as a group-disproportionately more than they are addressed as single individuals as well as disproportionately more than men are addressed as a collective group. Such patterns also mean that there are more sweeping characterizations of women than of men as a group, and that it is far more likely that an individual woman will be used to speak for and about women of her time than an individual man to do the same.

The discursive pattern of men-as-individuals and womenas-group is worth examining further because it suggests that how women are included and discussed in anthologies may still Other and tokenize them even as editors strive to draw attention to them. The corpuslinguistic examination of gendered pro/ nouns below offers a view of patterns like those above across time and apparatus texts.

\section{Examining Gendered Pro/Nouns Across Time and Anthologies}

Though uncommon in literary studies, corpus linguistic analysis complements single-text analysis. Particularly for studies like this one, interested in language use that recurs enough to shape collective expectations and impressions, corpus linguistics helps illuminate discourse patterns otherwise difficult to note in aggregation. Informed by and informing the rhetorical analysis above, the corpus linguistics analysis below quantifies the number of appearances of each gendered pronoun and noun in the apparatus of all editions of the Heath and Norton to help expose representation in ways distinct from human readers.

Given the reputations of the Norton (as more canonical) and the Heath (as more liberal), the comparative frequencies of gendered nouns and pronouns terms show compelling similarities and differences, which I represent graphically as well as in terms of ratios and raw numbers below. Figure 1 shows the distribution of all gendered pro/nouns in all prefaces and period overviews of editions 1 - 7 of the Norton Anthology of American Literature. Figure 2 shows the same ineditions 1 - 6 of the 
Heath Anthology of American Literature. The figures visually capture frequency differences between individual references and group references in the anthologies.

As Figures 1 and 2 reveal, in both anthologies, male referents account for the majority of gendered pro/nouns overall, and the female referent women appears more than men. But there are notable differences between the two anthologies. Female referants account for a much higher $44 \%$ of the total Heath distribution (Figure 2) compared to less than 25\% in the Norton (Figure 1). Another noteworthy difference between the two anthology's noun distribution is the frequent use of women in the Heath, over twice the word's frequency in the Norton.

Put in terms of relative frequencies over time, the Norton patterns change more than those of the Heath ${ }^{8}$. The preface and period overviews of the Heath $1^{\text {st }}$ edition (published in 1989) shows word frequencies that are not much different than those of the Heath $6^{\text {th }}$ edition (published in 2009): in the $1^{\text {st }}$ edition apparatus, the ratio of terms women to men is 34 to 11 , while the ratio of she to he is 7 to 22; the ratio of her ${ }^{9}$ to his/him is 18 to 36 . The similar ratios from the $6^{\text {th }}$ edition are: women to men, 28 to 10; she to he, 5 to 18; and her versus his/him, 15 to 32 . The Norton, in contrast, shows drastic change between its $1^{\text {st }}$ and $7^{\text {th }}$ edition. In the Norton $1^{\text {st }}$ edition (published in 1979), the ratio of terms women to men is 8 to 9 , while she versus he is grossly unbalanced at 2 to 46 . The ratio of her to his/him is 11 to 71 . In the Norton $7^{\text {th }}$ edition (published in 2007), the ratio of terms women to men changed to 19 to 6 , while the ratio of she to he changed to 5 to 23 and her to his/him changed to 14 to 43 . Overall, these ratios reflect change in the Norton over time and the general pattern of singular pronouns dominated by male referents and plural nouns dominated by the female referent.

These relative frequencies, which facilitate comparison between the anthologies, are striking; but the raw numbers across all editions of each anthology are equally striking when we imagine that thousands of students over time have encountered anthologies and read them without paying conscious attention to gender pro/noun patterns. In the apparatus of the Heath (all editions), the word men appears 801 times, compared to 2249 appearances of women. In the same texts, he appears 1836 times while she appears 477 times. In the corresponding apparatus of the Norton (all period overviews and prefaces of all editions), women appears 465 times compared to men appearing 231 times; in contrast, he appears 1224 times while she appears only 116 times $^{10}$.

\footnotetext{
${ }^{8}$ Here I am referring to relative, normalized frequencies in order to facilitate comparing the observed distributions across corpus texts that are different lengths (this is important given than Heath period overviews are generally longer than those of the Norton). The relative frequency of , for example, "women" in the Heath $1^{\text {st }}$ edition preface and period overviews can be obtained by dividing the number of occurrences of "women" (350) by the total number of words in these texts $(102,771)$. Since the resulting number (.0034056) is small and hard to interpret, we can additionally norm by an arbitrary value. Relative frequencies are typically normalized to ten thousand. In my example, then, the relative frequency of "women" in the Heath $1^{\text {st }}$ edition subcorpus would be $.0034056 * 10000=\mathbf{3 4 . 0 5 6}$, or 34 . I have rounded numbers to the nearest whole number, rounding the number up for all values .5 and higher, down for below .5 .

${ }^{9}$ The uses of "hers" in all texts and editions were too rare as to have above a .0 or .1 relative frequency (most often occurring fewer than 1 time per 100,000 words of editorial text), and this pronoun is thus not represented in the tables and charts.

${ }^{10}$ In these same texts, in the Heath: his appears 2553 times while her appears 1274 times; in the Norton: his appears 1874 times while her appears 464 times. These numbers are not normalized, as I compare them only within each anthology.
}

Norton: Distribution of gendered nouns and pronouns: Woman (all editions, all prefaces and overviews)

$2 \%$

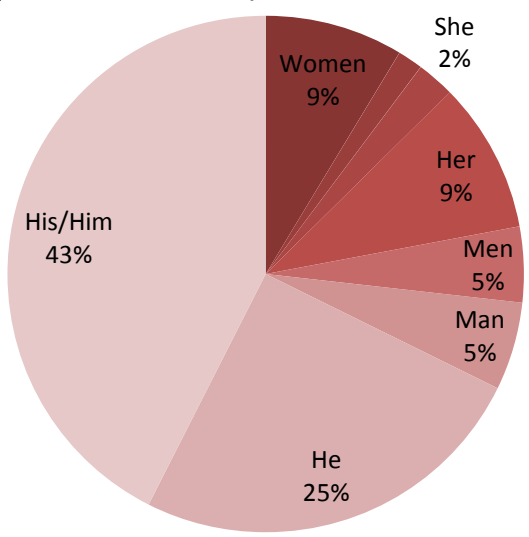

Figure 1.

Norton distribution of gendered nouns and pronouns across all editions.

Heath: Distribution of gendered nouns and pronouns (all editions)

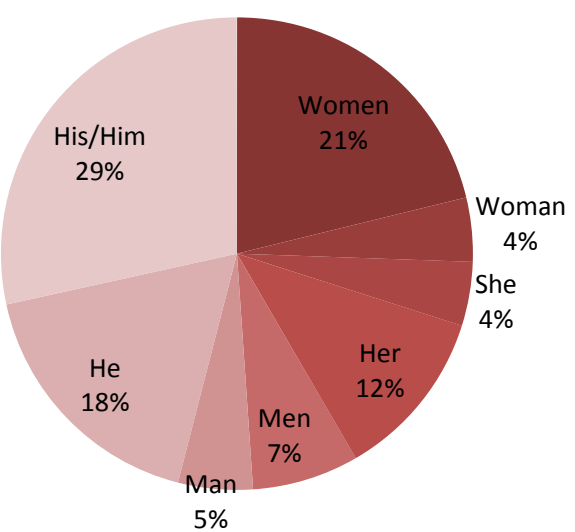

Figure 2.

Heath distribution of gendered nouns and pronouns across all editions.

Finally, in order to address the potential perception that greater detail about male individuals in US literary history is due to a scarcity of early historical records on US women (though the anthologies' alleged projects of "redressing” neglect of women writers and experiences stipulates historical recovery work on the part of the editors/anthology), it is worth noting that the pattern of references to male individuals and women as a group similar in analyses of only the most recent overviews and editions. In the contemporary overview of the most recent Heath, female referents account for $35 \%$ of the singular pronouns but $79 \%$ of the plural nouns. In the corresponding overview in the Norton, female references account for only $18 \%$ of the singular pronouns but $83 \%$ of the plural nouns ${ }^{11}$. As in the overall corpus trends, singular pro/nouns are overwhelmingly male referents, while gendered group titles show the opposite pattern.

Of my original speculations about the anthology apparatus - that Norton editions would move from little representation of women to increasingly balanced representation while the

\footnotetext{
${ }^{11}$ These frequencies come from the contemporary overviews (1945-present) in only the most recent edition of the Heath and the Norton (published in 2009 and 2007 respectively).
} 
Heath editions would achieve gender balance earlier and more consistently — only one turned out to be true: over time, Norton editorial texts mention more individual woman and reference women more as a group as well. Yet there is little equality in the details offered about women and men. Both the quantitative and rhetorical analysis reflect a pattern of more male pro/nouns in all singular references, particularly those most commonly used to provide more elaborate details about a named individual figure without renaming the figure (he and his). In contrast, the plural references are dominated by the female form women.

While such patterns can be noted in individual texts, their magnitude is difficult or impossible to grasp without such methods: close textual analysis helps make clear that singular pronouns are used in similar ways whether referring to females or males; coupled with corpus analysis, it becomes clear that nonetheless, male singular pronouns are used far more often. A combined rhetorical and corpus analysis of anthology apparatus reflects important discursive and thematic patterns which, regardless of the period, edition, or more traditional or revisionist orientation of the anthology, figuremen and women differently in the apparatus narrative of the canon. In two anthologies used in thousands of classrooms now and in the past, women appear to be an important group, with both the shackles and possibilities of being cast and understood primarily in terms of their gendered group. Men are cast primarily as important individuals, with both the opacity and opportunities inherent therein.

\section{Final Considerations: Quantitative Language Analysis and Canonical Awareness}

Before closing, I want to underscore claims related to my analytic approach, particularly vis-à-vis concerns about digital technologies and literary studies. The analysis above foregrounds an uncommon approach in anthology studies, which I have emphasized is mutually-generative. Written texts-and thus the social and textual expectations that inform themshape and are shaped by the rhetorical content of single texts as well as the effect of repeating patterns across texts; these patterns are not all visible in only single texts or only across many of them. Critical analysis of our textual world is accordingly enhanced by examination of both recurring patterns across texts as well as how those patterns are realized in individual texts.

This analytic approach also coincides with existing ideas related to teaching American literature. One of these ideas is that cultural texts from the literary to the everyday contain subtextual messages within them, and that part of our work as teachers and scholars is to uncover and interrogate those messages. A second, related idea is that part of critical reading and writing is re-viewing texts from different perspectives - of entering old texts from newly critical directions. In the case of a feminist perspective, Adrienne Rich has suggested such re-viewing can be "an act of survival" because it is only thus that we resist the "self-destructiveness" of a male-dominated society (18). Judith Fetterley suggests that this kind of feminist re-viewing of texts precedes the re-vision, or change, of sexist ideas (viii).

These two ideas - the importance of re-viewing texts and of recognizing the power of subtext-are related to the pedagogical concerns of the late $20^{\text {th }}$ century noted in the opening paragraph: that uninterrogated texts and practices can operate in our classrooms, and that university English courses can empower students with an alternative, critical perspective. The evidence in this study suggests that a combined qualitative and quantita- tive approach makes such re-viewing possible in literal and theoretical ways. Literally, the approach exposes quantitative patterns across many texts which are illuminated by critical reading of individual texts; more theoretically, it casts individual texts as working in intertextual, dialectic relation to other texts, a notion that challenges understandings based on more linear reading practices.

These possibilities take on particular exigency in light of the recent publication of Google's Ngram Viewer ${ }^{12}$, a searchable corpus of the 500 million books digitized by Google in recent years. Described as a "New Window on Culture" in the New York Times, this corpus is indeed by far the largest corpus in the world $^{13}$. Yet while it allows an exciting look at the changing quantities of particular words and phrases in books across time, it does not suggest the importance of the textual contexts of those same words and risks glossing over the value of combining quantitative data with more qualitative analysis.

In a simple example, consider Figure 3, which shows the appearances of women (blue line) and men (red line) from 19802000 in the Google books corpus.

The image in Figure 3 offers acompelling pattern: in these 500 million digitized books, references to women clearly surpassed references to men at some point in the mid-1980s. Such a shift speaks to important changes in cultural values and linguistic practices. Yet without a view of the actual texts, we miss crucial information: for example, how often women appears alone versus in phrases with men (e.g., American men and women), or how often references to men are meant to imply all human beings, or only men. Likewise, we cannot tell whether these references are written by men or women or in what kinds of texts they are most likely to appear. Even these basic details would be important for illuminating what these patterns tell us about shifts in cultural values vis-à-vis the use of the terms women and men. Accordingly, a risk for this kind of quantitative approach in scholarship and in teaching is that it glosses over the important work done in individual examples and in particular genres. It can offer a way into texts, but should not stop there; for example, this same search could be the impetus for a closer look at texts published between the years of 1984-1988, which appears to be a significant time in the history of these words in books written in English. These directions could be further refined using a corpus with more context surrounding each word, like COCA or COHA, which allows for comparisons across different kinds of books ${ }^{14}$. Such a dual way into texts underscores the importance of rhetorical features as they contribute to persistence and change in widely-circulating texts such as anthologies. And it challenges us to consider that some of the power of texts and linguistic norms are precisely those we do not always see unless we re-view them in newly critical ways.

The notion that it is not enough to only "include" underrepresented groups in the canon is not new. But there is not a surefire way to do more, especially in anthologies that simultaneously narrate traditionally-represented voices. This study shows one clear manifestation of the problematics of inclusion without rethinking (discursive) exclusion, in efforts to aid

\footnotetext{
${ }^{12}$ For more, see http://ngrams.googlelabs.com/

${ }^{13}$ http://www.nytimes.com/2010/12/17/books/17words.html

${ }^{14}$ See http://corpus.byu.edu/coha/compare-googleBooks.asp for a description by COCA/COHA founder Mark Davies of why COCA "often produces much more insightful analyses for cultural and societal shifts" than Google’s new corpus.
} 


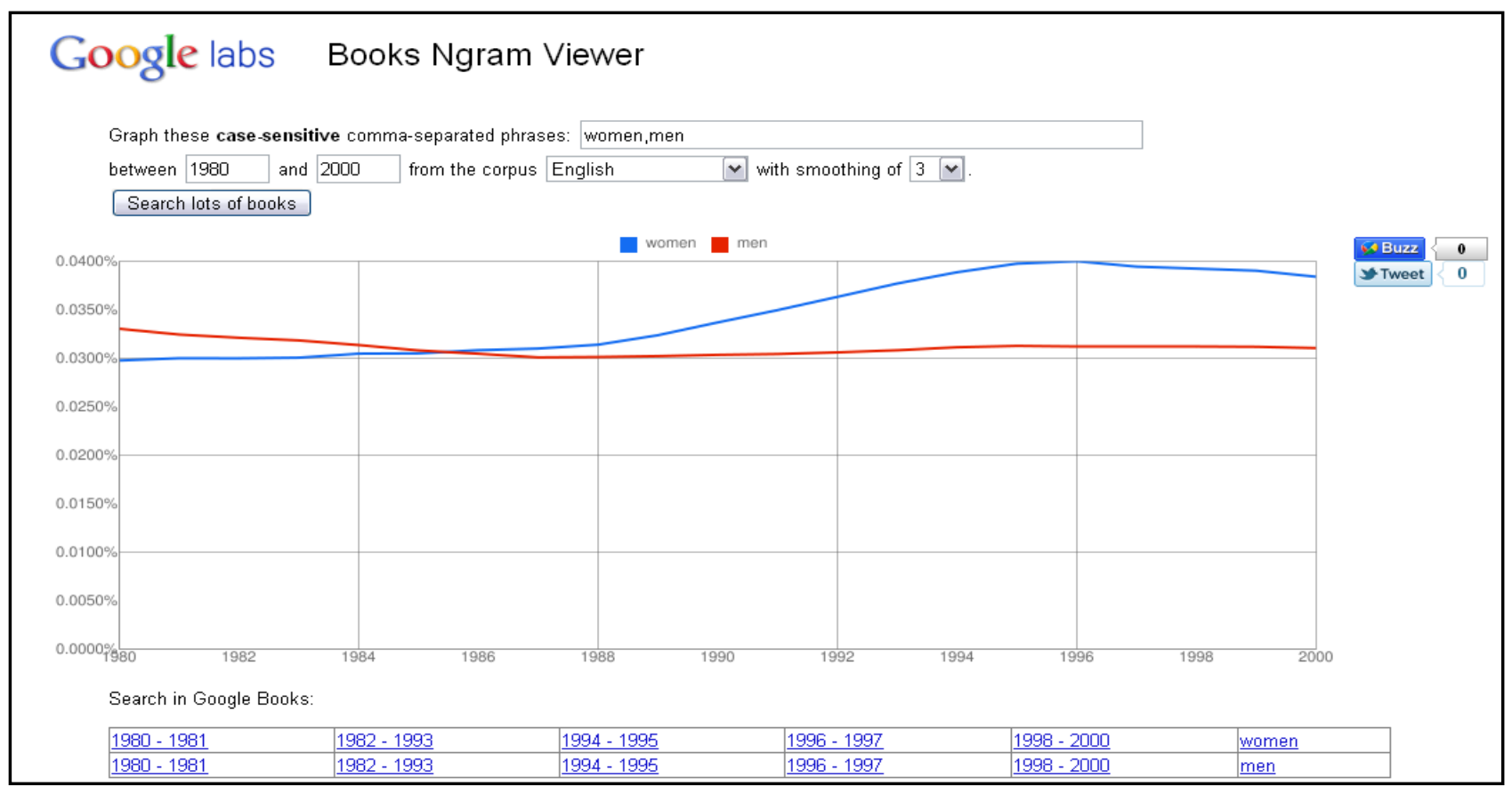

Figure 3.

Google Ngram view of use of women, men over time.

editorial and pedagogical re-vision practices. Women included but referred to primarily as a single group, alongside men referred to primarily as individuals, may largely reinforce a "gender-asymmetric culture” (Nina Baym, 2002a) by glossing over individuation and group socialization for women and men. Put another way, at stake in such discourse patterns for scholars and teachers is not only the importance of portraying individual women who have made an impact in US cultural history but also attending to the significance of all gendered socialization and to the often-subtle ways that it occurs. We want instead to rethink what we already know and assume through what we newly understand and include in our histories and canons (Robinson, 1987: pp. 26-27). We have new possibilities for that kind of work, for analyzing national, literary narratives and examining the myriad ways we discursively include and exclude certain people and groups. Such practices help us respond to $20^{\text {th }}$-century cries for change in $21^{\text {st }}$-century ways: new ways to do more than add and stir, or add and other: new ways to change the world by "changing the consciousness of those who read and their relations to what they read" (Fetterley, 1978: p. viii).

\section{REFERENCES}

Anthony, L. (2005). Antconc (Version 3.2.1). Tokyo: Laurence Anthony, University of Waseda.

Arac, J. (2008). What Good Can Literary History Do? American Literary History, 20, 1-11. http://dx.doi.org/10.1093/alh/ajm053

Aull, L. L. (2012). Students creating canons. Pedagogy: Critical Approaches to Teaching Literature, Language, Composition, and Culture, 12. http://dx.doi.org/10.1215/15314200-1625271

Baym, N. (1989). The Norton anthology of American literature (3rd ed.). New York: Norton.

Baym, N. (1995). The Norton anthology of American literature (4th ed.). New York: Norton.
Baym, N. (2002a). Plenary remarks. Legacy, 19, 1. http://dx.doi.org/10.1353/leg.2003.0002

Baym, N. (Ed.) (1998). The Norton anthology of American literature (5th ed.). New York: W.W. Norton.

Baym, N. (Ed.) (2002b). The Norton anthology of American literature (6th ed., Vol. E). New York: Norton.

Baym, N., et al. (Ed.) (2007). The Norton anthology of American literature (7th ed.). New York: W. W. Norton and Company.

Baym, N., et al. (1985). The Norton anthology of American literature (2nd ed.). New York: Norton.

Bennett, P. (1991). Canons to the Right of Them... The Women's Review of Books, 8, 15-16. http://dx.doi.org/10.2307/4020997

Brown, J. L. (2010). Constructing our pedagogical canons. Pedagogy, 10, 535-553.

Csicsila, J. T. (1998). Canons by consensus: Critical trends and American literature anthologies. Las Vegas, Nevada: University of Nevada.

http://proquest.umi.com.proxy.lib.umich.edu/pqdweb?did=73288626 1 \&Fmt $=7$ \&clientId $=17822 \&$ RQT $=309 \&$ VName $=$ PQD

Dyer, M. (2001). Invitation to anthologize. In A. R. Gere, \& P. Shaheen (Eds.), Making American literatures in high school and college (pp. 10-16). Urbana, Ill.: National Council of Teachers of English.

Egan, J. (1997). Analyzing the Apparatus: Teaching American Literature Anthologies as Texts. Early American Literature, 32, 102-108.

Elmer, J. (2008). A Response to Jonathan Arac. American Literary History, 20, 12-21. http://dx.doi.org/10.1093/alh/ajn004

Fetterley, J. (1978). The resisting reader: A feminist approach to American fiction. Bloomington: Indiana University Press.

Frow, J. (2006). Genre. London, New York: Routledge.

Genette, G., \& Maclean, M. (1991). Introduction to the Paratext. New Literary History, 22, 261-272. http://dx.doi.org/10.2307/469037

Gottesman, R., Murphy, F., Holland, L. B., Parker, H., Kalstone, D., \& Pritchard, W. (1979). The Norton anthology of American literature (1st ed., Vol. 1). New York: Norton.

Graff, G. (1987). Professing literature: An institutional history.

Guillory, J. (1993). Cultural capital: The problem of literary canon formation. Chicago: University of Chicago Press.

http://dx.doi.org/10.7208/chicago/9780226310015.001.0001

Jay, G. S. (1991). The End of “American” Literature: Toward a Multi- 
cultural Practice. College English, 53, 264-281.

http://dx.doi.org/10.2307/378101

Lauter, P. (1983). Reconstructing American literature: Courses, syllabi, issues. Old Westbury, N.Y.: Feminist Press.

Lauter, P. (1991). Canons and contexts. New York: Oxford University Press.

Lauter, P., \& Bruce, N. (1990). The Heath anthology of American literature. Lexington, Mass.: D.C. Heath.

Lauter, P., et al. (Ed.). (2002). The Heath anthology of American literature (4th ed.). Boston: Houghton Mifflin Co.

Lauter, P., et al. (Ed.). (2005). The Heath anthology of American literature (5th ed.). Boston: Houghton Mifflin Co.

Lauter, P., et al. (Ed.). (2009). The Heath anthology of American literature (6th ed.). Boston: Houghton Mifflin Co.

Lauter, P., Yarborough, R., \& Bruce, N. (1994). The Heath anthology of American literature (2nd ed.). Lexington, Mass.: D.C. Heath and Co.

Lauter, P., Yarborough, R., \& Bruce, N. (1998). The Heath anthology of American literature (3rd ed.). Boston: Houghton Mifflin Co.
Lockard, J., \& Sandell, J. (2008). National Narratives and the Politics of Inclusion: Historicizing American Literature Anthologies. Pedagogy, 8, 227-254.

Papadima, L., Damrosch, D., \& D’haen, T. (2011). The Canonical Debate Today: Crossing Disciplinary and Cultural Boundaries: Rodopi.

Robinson, L. S. (1987). Canon Fathers and Myth Universe. New Literary History, 19, 23-35. http://dx.doi.org/10.2307/469299

Ruland, R. (1991). Art and a Better America. American Literary History, 3, 337-359. http://dx.doi.org/10.1093/alh/3.2.337

Shesgreen, S. (2009). Canonizing the Canonizer: A Short History of The Norton Anthology of English Literature. Critical Inquiry, 35, 293-318. http://dx.doi.org/10.1086/596644

Shumway, D. R. (1994a). American Literature in the Currriculum Creating American civilization: A genealogy of American literature as an academic discipline. Minneapolis: University of Minnesota Press.

Shumway, D. R. (1994b). Creating American civilization: A genealogy of American literature as an academic discipline. Minneapolis: University of Minnesota Press. 